\title{
Multiple Dopamine Receptor Subtypes in the Medial Prefrontal Cortex of the Rat Regulate Set-Shifting
}

\author{
Stan B Floresco*,', Orsolya Magyar', Sarvin Ghods-Sharifi', Claudia Vexelman' and Maric TL Tse' \\ 'Department of Psychology and Brain Research Center, University of British Columbia, Vancouver, BC, Canada
}

\begin{abstract}
Dopamine (DA) input to the prefrontal cortex (PFC), acting on DI receptors, plays an essential role in mediating working memory functions. In comparison, less is known about the importance of distinct PFC DA receptor subtypes in mediating executive functions such as set-shifting. The present study assessed the effects of microinfusion of D2 and D4 receptor antagonists, and DI, D2, and D4 receptor agonists into the PFC on performance of a maze-based set-shifting task. In Experiment I, rats were trained on a response discrimination task, and then on a visual-cue discrimination task requiring rats to suppress the use of the response strategy and approach the previously irrelevant cue to locate food. In Experiment 2, the order of training was reversed. Infusions of the D2 antagonist eticlopride, or the D4 agonist PD-168,077, impaired shifting from a response to a visual-cue discrimination strategy and vice versa, and caused a selective increase in perseverative errors. In contrast, infusions of the D4 antagonist L-745,870 improved set-shifting. Infusions of the DI agonist SKF8I297 or the D2 agonist quinpirole caused no reliable effect. These data, in combination with previous reports of impaired setshifting following DI receptor blockade, suggest that multiple receptors in the PFC are essential for set-shifting and that the mechanisms by which PFC DA mediates behavioral flexibility may be different from those underlying working memory. These findings may have important implications for developing novel treatments for cognitive deficits observed in disorders such as attentional deficit and hyperactivity disorder and schizophrenia.

Neuropsychopharmacology (2006) 3 I, 297-309. doi:I 0. I038/sj.npp. I 300825; published online I 3 July 2005
\end{abstract}

Keywords: frontal lobe; dopamine; D4 receptor; schizophrenia; ADHD; rat

\section{INTRODUCTION}

Mesocortical dopamine (DA) plays a well-established role in mediating working memory processes governed by the prefrontal cortex (PFC). Studies in both primates and rodents have revealed that DA depletion or pharmacological blockade of D1 (but not D2) DA receptors in the PFC impairs performance on a variety of delayed response tasks (Brozowski et al, 1979; Seamans et al, 1998). In addition, D1 receptor activity can modulate working memory in accordance with an 'inverted U-shaped' function, whereby either blockade or suprastimulation of D1 receptors in the PFC can impair performance (Zahrt et al, 1997; Romanides et al, 1999; Floresco and Phillips, 2001). Furthermore, the effects of D1 receptor activity on PFC function are in turn dependent on the relative levels of baseline performance; if baseline levels are low, then increased stimulation of PFC D1 receptors can improve working memory (Floresco and Phillips, 2001; Chudasama and Robbins, 2004; Phillips et al,

\footnotetext{
*Correspondence: Dr SB Floresco, Department of Psychology and Brain Research Center, University of British Columbia, 2136 West Mall, Vancouver, BC, Canada, V6T IZ4, Tel: + I 604827 53I3, Fax: + I 604822 6923, E-mail: floresco@psych.ubc.ca

Received 8 April 2005; revised 22 May 2005; accepted 2 June 2005 Online publication: 9 June 2005 at http://www.acnp.org/citations/ Npp060905050235/default.pdf
}

2004). Further elucidation of the mechanisms by which DA modulates working memory comes from electrophysiological studies in behaving primates, which have shown that DA enhances and stabilizes task-related firing of PFC neurons relative to background activity (Sawaguchi et al, 1990; Williams and Goldman-Rakic, 1995).

Dopaminergic modulation of PFC neural activity is regulated by multiple DA receptor subtypes. D1 receptor activation has both excitatory and inhibitory effects on synaptic activity in the PFC, augmenting excitatory NMDAmediated synaptic responses on pyramidal cells, but also enhancing GABAergic transmission (Zheng et al, 1999; Seamans et al, 2001a,b; Tseng and O'Donnell, 2004). In contrast, D2 receptors, which reside on pyramidal cells, local circuit interneurons, and presynaptic terminals (Vincent et al, 1993; Sesack et al, 1995) reduce the excitability of PFC projection neurons while at the same time attenuating GABAergic activity (Seamans et al, 2001a; Tseng and O'Donnell, 2004; Trantham-Davidson et al, 2004). D4 receptors have also been localized in the PFC (Mrzijak et al, 1996; Ariano et al, 1997; Wedzony et al, 2000), and have been shown to reduce both GABAergic and NMDA-mediated transmission (Wang et al, 2002, 2003). With respect to the specific functional roles of each of these DA receptor subtypes, most studies have focused on working memory processes. These studies 
have shown primarily a selective role for PFC D1 receptors, although systemic administration of D2 antagonists such as haloperidol have also been shown to disrupt delayed alternation in monkeys, but not rats (Murphy et al, 1996). However, the effects that local manipulation of D2 and D4 receptors within the PFC exert on other cognitive operations mediated by the frontal lobes have yet to be fully elucidated.

In addition to working memory, the PFC mediates cognitive operations entailing the coordination, manipulation, and flexible use of information from multiple memory systems that have been termed 'executive functions' (Baddeley, 1998; Fuster, 2000). For example, shifting of attentional set requires an organism to inhibit the use of a previously effective behavioral strategy and instead attend to previously irrelevant stimuli in order to obtain a goal. Both working memory and set-shifting are critically dependent on PFC; yet, each of these functions engages different cognitive processes. Working memory requires the active maintenance and manipulation of trial-unique information in a short-term memory buffer (GoldmanRakic, 1995; Seamans et al, 1998; Fuster, 2000). In contrast, an important component of set-shifting requires the organism to exert inhibitory control over the tendency to engage in a previously relevant behavioral strategy, which may be viewed as a form of extinction learning (Dias et al, 1997; Lebron et al, 2004). Humans with damage to the dorsolateral PFC, or those diagnosed with schizophrenia or attentional deficit and hyperactivity disorder (ADHD), display marked perseverative impairments when performing the Wisconsin Card Sorting task, a neuropsychological test used commonly to assess cognitive flexibility (Pantelis et al, 1999; Reeve and Schandler, 2001; Yang et al, 2004). Accordingly, preclinical animal studies have also shown that manipulations of the PFC impair performance on a number of tasks which require animals to behave in a flexible manner and shift attentional set. Specifically, lesions to the dorsolateral PFC in marmosets cause a selective impairment on extradimensional shifts, while having no effect on reversal learning (Dias et al, 1997). In rats, lesions or blockade of NMDA receptors in the medial PFC impairs setshifting on a number of tasks and causes a selective increase in perseverative errors, whereas the learning and maintenance of a new strategy remains unaffected (Ragozzino et al, 1999; Birrell and Brown, 2000; Stefani et al, 2003).

Surprisingly, there have been few studies investigating the importance of PFC DA transmission in attentional setshifting. In one study (Ragozzino, 2002), blockade of D1 receptors in the medial PFC of rats impaired shifting from a visual discrimination strategy to a response strategy and vice versa, while having no effect on the learning of either discrimination on its own, in a manner similar to that observed following reversible inactivation of the PFC (Ragozzino et al, 1999). In contrast, Roberts et al (1994) showed that depletion of DA in the dorsolateral PFC of marmosets improved extradimensional shifting, but disrupted performance on a spatial delayed response task, although a subsequent study revealed these effects to be due to a disruption in developing an initial attentional set (Crofts et al, 2001). However, the use of 6-hydroxydopamine lesions in this study did not permit for an assessment of the specific DA receptor subtypes that mediated these effects. Accordingly, it is possible that a more specific pharmacological investigation of the functional importance of distinct DA receptor subtypes in the PFC may further clarify the dopaminergic mechanisms that regulate setshifting. With this in mind, the present study investigated the functional roles that D1, D2, and D4 receptors in the medial PFC play in attentional set-shifting using intracranial microinfusions of selective DA receptor agonists and antagonists. In doing so, we utilized a similar set-shifting protocol described by Ragozzino (2002), which has been shown to be sensitive to blockade of D1 receptors in the PFC.

\section{MATERIALS AND METHODS}

\section{Apparatus}

Two identical four-arm cross mazes were used. The mazes were made of $1.5 \mathrm{~cm}$ thick plywood and painted white. Each arm was $60 \mathrm{~cm}$ long and $10 \mathrm{~cm}$ wide, with $20 \mathrm{~cm}$ high walls on each arm and with cylindrical food wells $(2 \mathrm{~cm}$ wide $\times 1 \mathrm{~cm}$ deep) drilled into the end of each of the arms, $2 \mathrm{~cm}$ from the end wall. Four removable table legs attached to the ends of each arm elevated the mazes $70 \mathrm{~cm}$ above the floor. Removable pieces of white opaque plastic $(20 \mathrm{~cm} \times 10 \mathrm{~cm})$ were used to block the arms of the maze to form a ' $T$ ' configuration. One maze resided in a $3 \mathrm{~m} \times 3 \mathrm{~m}$ room and the other in a room measuring $3.4 \mathrm{~m} \times 3.4 \mathrm{~m}$. An individual rat was assigned to one particular testing room throughout the course of habituation and testing.

\section{Subjects and Surgery}

Long Evans rats (300-400 g, Charles Rivers, Montreal, QC) were anesthetized with $100 \mathrm{mg} / \mathrm{kg}$ of ketamine hydrochloride and $7 \mathrm{mg} / \mathrm{kg}$ xylazine, and implanted with bilateral 23-gauge stainless-steel guide cannulae into the prelimbic region of the medial PFC (flat skull: $\mathrm{AP}=+3.0 \mathrm{~mm}, \mathrm{ML}=$ $\pm 0.7 \mathrm{~mm}$ from bregma, and $\mathrm{DV}=-2.7 \mathrm{~mm}$ from dura). obdurators flush (30-gauge) with the end of the guide cannulae remained in place until the injections were made. Each rat was given at least 7 days to recover from surgery prior to training. During this recovery period, animals were food restricted to $85 \%$ of their free feeding weight and were handled for at least $5 \mathrm{~min}$ per day.

\section{Habituation Procedure}

The habituation and set-shifting procedures were similar to those described by Ragozzino (2002). This task differs from other types of perceptual set-shifting paradigms in that it places a heavier emphasis on response conflict, although it also requires the animal to shift attention from one stimulus dimension to another (eg, turn direction $v s$ visual cues) (Slamecka, 1968; Birrell and Brown, 2000). We chose this particular task to permit for a direct comparison between the findings of the present study and the effects of D1 receptor antagonism reported by Ragozzino (2002).

On the day prior to their initial exposure to the maze environment, rats were given $\sim 30$ sweetened food reward pellets (Bioserv, Frenchtown, NJ) in a glass dish placed in their homecages, which was removed once all of the pellets 
were eaten. On the first day of habituation, five reward pellets were placed in each of the arms of the maze (three down the length of the arm and two in the food well). A rat was placed in the maze and allowed to freely navigate and consume the food pellets for $15 \mathrm{~min}$. If a rat consumed all 20 pellets prior to $15 \mathrm{~min}$, it was removed from the maze and placed in a holding cage, the maze was rebaited with 12 additional pellets, and the rat was placed back in the center of the maze. On the second habituation day, arms were only baited with three pellets each (two in the food wells and one in the center of the arms). Whenever a rat traversed the entire length of an arm and consumed the two food pellets in the well, it was picked up and placed at the entrance of a different arm. This procedure was intended to habituate the animal to repeated handling after consuming food reward. Subsequent habituation sessions were similar to the second day, except that only one food pellet was placed at the end of each arm. This procedure continued until the rat had consumed all four food pellets on the maze at least four times in the $15 \mathrm{~min}$ period. Rats required an average of $5.4 \pm 0.3$ days of habituation, (range 3-18 days) to reach this habituation criterion, and there were no differences between groups on this measure $(F(10,83)=1.28, \mathrm{NS})$.

On the last day of habituation, the turn bias for the rat was determined. The white opaque Plexiglas insert was placed at the entrance of one of the arms, forming a ' $\mathrm{T}$ ' configuration. A rat was placed in from the stem arm and allowed to turn left or right to obtain a food pellet. In one of the choice arms, a black and white striped, laminated piece of posterboard $(9 \mathrm{~cm} \times 20 \mathrm{~cm} \times 0.3 \mathrm{~cm})$ serving as a visual cue was placed on the floor. After a rat chose an arm and consumed a food pellet, it was picked up, placed in the stem arm, and allowed to make the next choice. If the rat chose the same arm as the initial choice, it was returned to the stem arm until it chose the other arm and consumed the food pellet. After choosing both arms, the rat was returned to the holding cage, the Plexiglas barrier and visual-cue were moved to different arms, and a new trial commenced. Thus, a trial for the turn-bias procedure consisted of entering both choice arms and consuming the food pellet. The turn that a rat made first during the initial choice of a trial was recorded and counted toward its turn bias, and the direction (right or left) that a rat turned four or more times over seven trials was considered its turn bias. After determining the turn bias, a rat's obdurators were removed from the guide cannulae and two injection cannulae were inserted for $2 \mathrm{~min}$, but no solution was injected at this time. This procedure was performed to habituate the animal to the two infusions they would receive over the next 2 days of testing. Response (Experiment 1) or visual-cue (Experiment 2) discrimination training commenced on the following day.

\section{Experiment 1: Response-Visual-Cue Set-Shifting Procedure}

Day 1: response discrimination training. For this discrimination, the animal was required to always turn in the opposite direction of its turn bias (left or right), regardless of the location of the visual cue placed in one of the arms (see Figure 1, top panels). Over the course of training, one of three start arms was used, to discourage animals from using an allocentric spatial strategy to locate the food. On day 1 of training, a rat was started from the arms designated west, south, and east (W, S, and E, respectively). The location of these arms relative to the spatial cues in the room was varied across animals, so that the maze was placed in one of four possible orientations. For every trial, the visual cue was placed in one of the choice arms so that over every consecutive set of 12 trials it was placed an equal number of times in each choice arm. The order of the start location for each trial as well as the position of the visual cue were determined pseudorandomly and taken from a preset sequence that was identical for each animal. On an individual trial, the rat was placed in the stem arm and required to make the appropriate turn in order to receive a food pellet. Between trials a rat was placed back in the holding cage on a bench adjacent to the maze. The intertrial interval was $\sim 15 \mathrm{~s}$. A rat continued to receive training trials until it reached a criterion of 10 correct consecutive choices. There was no limit on the number of trials a rat was allotted to reach this criterion. After the rat achieved this acquisition criterion, it received a probe trial; this consisted of starting the rat from the fourth arm (north, N) that was not used as a start arm during testing. During probe trials, the visual cue was inserted in the arm opposite to the direction that the rat was required to turn. If a rat correctly turned the same direction as was required during training, then response discrimination training was completed. If a rat made an incorrect turn, response training was continued until a rat made an additional five correct choices consecutively, at which time another probe trial was administered. This procedure was continued until a rat made a correct choice on the probe trial. The following measures were taken for each rat and used for data analysis: (1) trials to criterion, defined as the total number of test trials completed before a correct choice on the probe trial was made and (2) probe trials, defined as the total number of probe trials an animal required to get one correct. The time it took to complete training was also recorded. If a rat did not complete at least 30 trials within the first hour of training, training was discontinued and the animal's data were excluded from the analysis.

Day 2: shift to visual-cue learning. The day after reaching criterion on the response version, rats were now trained to enter the arm that contained the visual cue, the location of which was pseudorandomly varied in the left and right arms such that it occurred in each arm with equal frequency for every consecutive set of 12 trials (see Figure 1, bottom panels). The training procedure was similar to that used in the response version. The same start arms and criteria to complete the visual-cue version were used as described in the response version. For probe trials, the visual cue was always placed in the arm opposite to that which the rat had been trained to enter during response discrimination training.

Errors were scored as entries into arms that did not contain the visual cue, and were further broken down into three error subtypes to determine whether treatments altered the ability to either shift from the previously learned strategy (perseverative errors) or to maintain the new strategy after perseveration had ceased (regressive or never- 

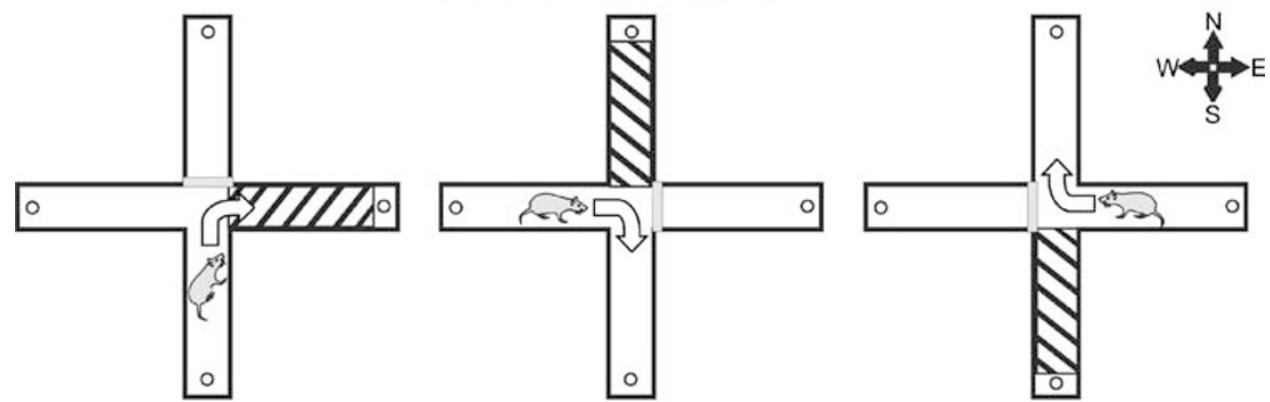

Visual-Cue Version (Day 2)
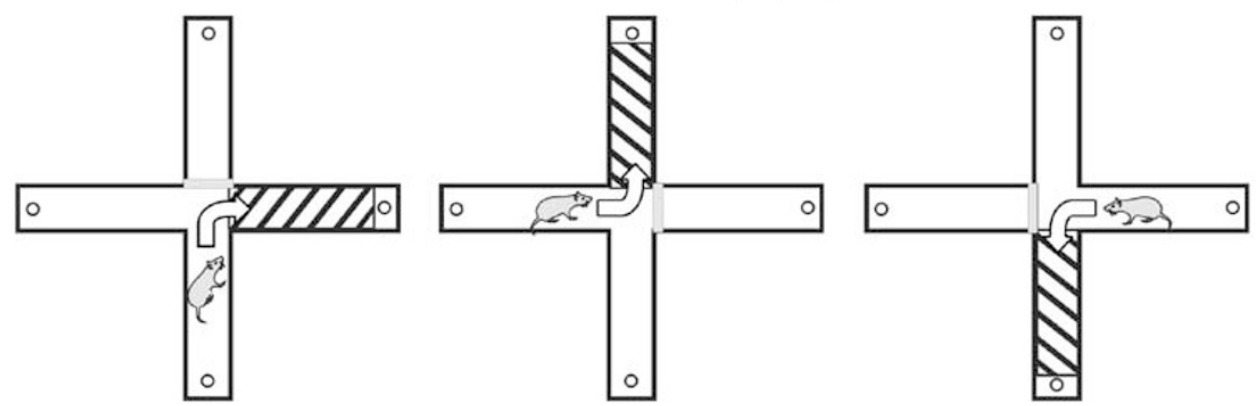

Figure I Example of the attentional set-shifting task used in Experiment I. The arrows in the maze represent the correct navigation pattern to receive reinforcement. During initial response discrimination training on day I (upper panels), in this example, the rat was started from the south (S), west (W), and east (E) arms, and always had to make a $90^{\circ}$ turn to the right to receive food reinforcement. A black and white striped visual cue was randomly placed in one of the choice arms on each trial, but did not reliably predict the location of food during response training. During the set-shift on day 2 (lower panels), the rat is required to use a visual-cue discrimination strategy. Here, the rat was started from the same arms but had to always enter the arm with visual cue, which could require either a right or a left turn. Thus, the rat must shift from the old strategy and attend to the previously irrelevant cue in order to obtain reinforcement.

reinforced errors). A perseverative error was scored when a rat continued to make the same egocentric response as required on the response version on those trials that required the rat to turn in the opposite direction to enter the arm containing the visual cue. Six of every 12 consecutive trials required the rat to respond in this manner (ie, enter the arm opposite of the previously learned turn direction). As described in previous studies (Dias and Aggleton, 2000; Ragozzino et al, 1999; Ragozzino, 2002), these trials were separated into consecutive blocks of four trials each. Perseverative errors were scored when a rat entered the incorrect arm on three or more trials per block of four trials. Once a rat made less than three perseverative errors in a block for the first time, all subsequent errors were no longer counted as perseverative errors, because at this point the rat was choosing an alternative strategy at least half of the time. Instead, these errors were now scored as regressive errors. The third type of error, termed 'neverreinforced' errors, was scored when a rat entered the incorrect arm on trials where the visual cue was placed in the same arm that the rat had been trained to enter on the previous day. For example, during training on day 1, a rat might be required to turn left. During the shift on day 2, a rat must now enter the arm with the visual cue, and for half of the trials the cue was in the left arm. In this situation, a never-reinforced error was scored when a rat entered the right arm (ie, a choice that was not reinforced on either day 1 or day 2). The combination of regressive and never-reinforced errors has been used as an index of the animals' ability to maintain a new strategy.

\section{Experiment 2: Visual-Cue-Response Set-Shifting Procedure}

For these experiments, rats were initially trained on the visual-cue version of the task on day 1 , followed by testing on the response version on day 2 . All other aspects of the testing procedure were identical to those described above. On the shift to the response version, the same measures were assessed as those for Experiment 1, where rats were required to shift from a response to a visual-cue strategy. However, perseverative and regressive errors were analyzed from the trials in which a rat was required to turn in the arm opposite to that of the visual cue.

\section{Drugs and Microinfusion Procedure}

The effects of five dopaminergic compounds (two antagonists and three agonists) were tested. All drugs were mixed fresh for each experiment in physiological saline, sonicated until dissolved, and protected from light. The drugs and doses tested were as follows: the D2 receptor antagonist eticlopride hydrochloride $(0.1$ and $1 \mu \mathrm{g}$; Sigma Aldrich, Canada), the D4 receptor antagonist L-745,870 (1.0 and $10.0 \mu \mathrm{g}$; Tocris Biosciences), the D1 receptor agonist SKF 81297 (0.06 and $0.2 \mu \mathrm{g}$; Tocris), the D2 receptor agonist 
quinpirole hydrochloride (1.0 and $10.0 \mu \mathrm{g}$; Sigma), and the D4 receptor agonist PD-168,077 (0.1 and $1.0 \mu \mathrm{g}$; Sigma). The doses of eticlopride, L-745,870, SKF 81297, and quinpirole were chosen from previous studies which have shown alterations in behavior following administration of these drugs into the PFC (Beyer and Steketee, 2000; Floresco and Phillips, 2001; Chudasama and Robbins, 2004, Shah et al, 2004; Sun and Rebec, 2005).

Infusions of all drugs and saline were administered bilaterally into the PFC via 30 -gauge injection cannulae that protruded $0.8 \mathrm{~mm}$ past the end of the guide cannulae, at a rate of $0.5 \mu 1 / 72 \mathrm{~s}$, by a microsyringe pump (Sage Instruments Model 341). Injection cannulae were left in place for an additional $1 \mathrm{~min}$ to allow for diffusion. Each rat remained in its home cage for a further 10 -min period prior to behavioral testing.

Previous studies have shown that manipulations of the PFC do not disrupt the initial learning of either a response or visual-cue-based discrimination (Ragozzino et al, 1999; Chudasama et al, 2001; Ragozzino, 2002). Rather, PFC manipulations only disrupt behavior when rats are required to shift from one strategy to another (Ragozzino et al, 1999; Ragozzino, 2002; Stefani et al, 2003). As such, we were not interested in the effects of intra-PFC infusions of DA compounds during initial discrimination learning, and on day 1 rats in all groups received a saline infusion into the PFC. The assignment of a rat to a particular drug treatment group was counterbalanced based on the number of trials to reach the criterion on day 1 of training, so that all rats in all groups took roughly the same number of trials to learn the task on day 1. DA receptor agonists or antagonists were infused prior to testing on day 2. For Experiment 1, we assessed the effects of two doses of each drug. For Experiment 2, we only tested the lowest dose, or most effective dose of each drug that produced statistically significant alterations of behavior in Experiment 1.

\section{Histology}

Upon completion of behavioral testing, the rats were killed in a carbon dioxide chamber. Brains were removed and fixed in a $4 \%$ formalin solution. The brains were frozen and sliced in $50 \mu \mathrm{m}$ sections prior to being mounted and stained with Cresyl Violet. Placements were verified with reference to the neuroanatomical atlas of Paxinos and Watson (1998). Rats with cannulae placements that were asymmetrical or located rostrally in the medial orbital cortex were excluded from the data analysis. The locations of infusions for all rats tested in Experiment 2 are displayed in Figure 2.

\section{Data Analysis}

The number of trials to reach the criterion on day 1 of training for each experiment were analyzed separately using a one-way analysis of variance (ANOVA) to confirm that all rats took an equivalent number of trials to learn the initial response or visual-cue discrimination. Trials to criterion data obtained from day 2 (set-shift) for each experiment were analyzed using separate two-way between/withinsubjects ANOVA, with Drug Treatment as the betweensubjects factor and Choice Type (Correct or Error) as the within subjects factor. Data regarding the types of error

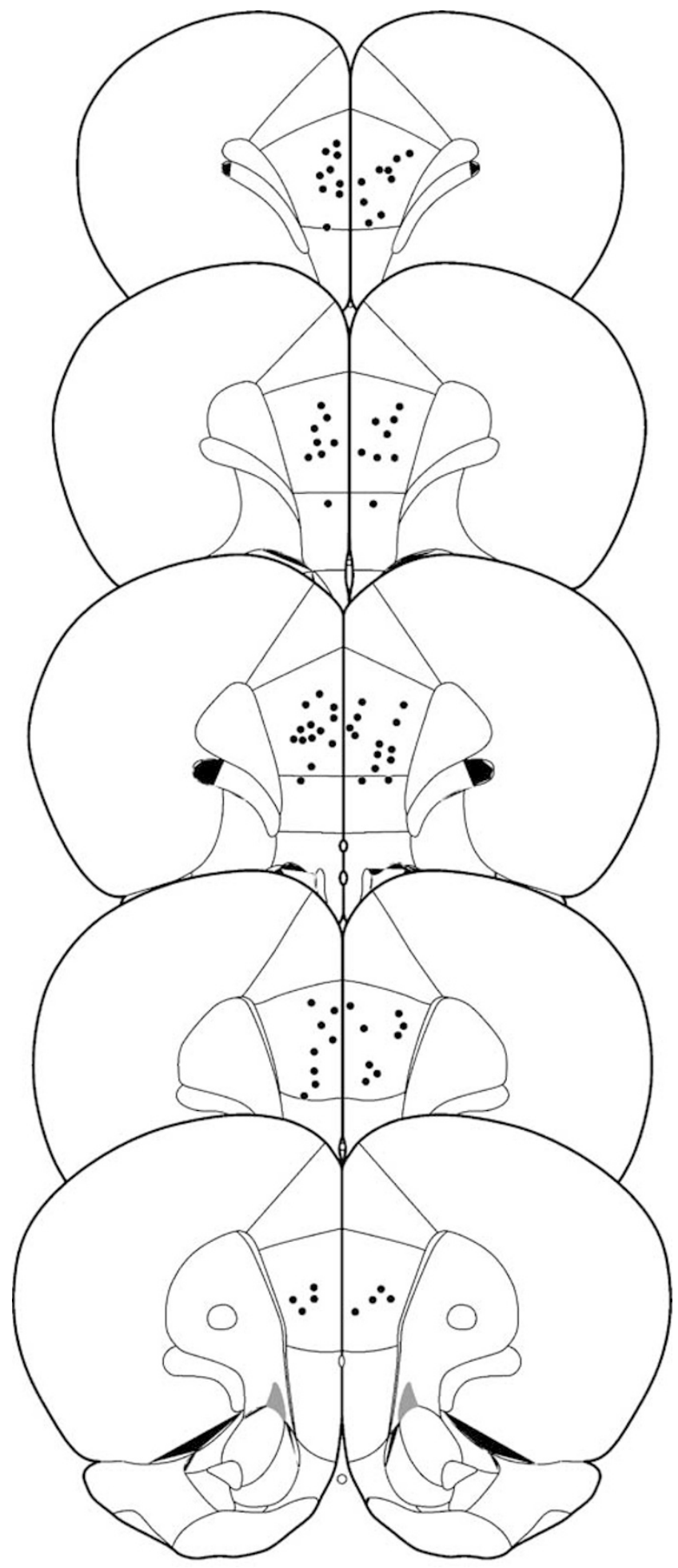

Figure 2 Histology. Schematic of coronal sections of the rat brain, showing the placements of the cannulae tips for all rats in Experiment 2 that received infusions of dopaminergic drugs or vehicle into the PFC. Brain sections correspond to the atlas of Paxinos and Watson (1998).

were analyzed separately using a two-way between/withinsubjects ANOVA, with Drug Treatment as the betweensubjects factor and Error Type (perseverative, regressive, or never-reinforced) as the within-subjects factor. When a significant main effect of Drug Treatment was observed, 
multiple comparisons were conducted using Dunnett's test. For measures of response latency, the total number of trials required to reach the criterion was divided by the total time required to reach criterion (trials per minute). These data were analyzed using separate one-way ANOVAs.

\section{RESULTS}

\section{Experiment 1}

Day 1: response discrimination training. All rats in all groups took an equivalent number of training trials to achieve criterion performance on day 1 of training when animals received a saline infusion into the PFC (mean $64.4 \pm 3.5 ; \quad F(10,83)=0.87$, NS; Figure 3a). Rats took $47.3 \pm 4 \mathrm{~min}$ to complete response discrimination training, and there were no significant differences between groups in the average trials per minute $(\mathrm{F}(10,83)=1.45$, NS). There were also no differences in the number of probe trials required to complete training on day 1 $(\mathrm{F}(10,83)=0.95, \mathrm{NS})$.
Day 2: shift to visual-cue discrimination. Analysis of the number of trials to reach the criterion on day 2 revealed a significant main effect of Drug Treatment $(\mathrm{F}(10,83)=4.94$, $p<0.001)$, and a significant effect of Choice type $(\mathrm{F}(1,83)=0.87, \mathrm{NS})$, indicating that all rats in all groups made more correct than incorrect choices over the course of training. There was no significant Treatment $\times$ Choice type interaction $(\mathrm{F}(10,83)=1.52$, NS). A separate analysis conducted on the errors committed during the set-shift revealed a significant main effect of Drug Treatment $(\mathrm{F}(10,83)=4.15, p<0.001)$, a significant effect of Error type $(\mathrm{F}(2,166)=5.15, p<0.01)$, and a significant Drug Treatment $\times$ Error Type interaction $(\mathrm{F}(20,166)=1.84, p<0.05)$. Rats receiving saline infusions into the $\operatorname{PFC}(n=10)$ required $65.1 \pm 5$ trials and $34.5 \pm 4$ min to achieve criterion performance (Figure $3 \mathrm{~b}$ and e, white bar), and made an equivalent number of perseverative, regressive, and never-reinforced errors (Figure 4, white bars). A separate one-way ANOVA conducted on the latency data showed no significant difference between treatment groups on the average number of trials completed per minute

\section{DA antagonists}

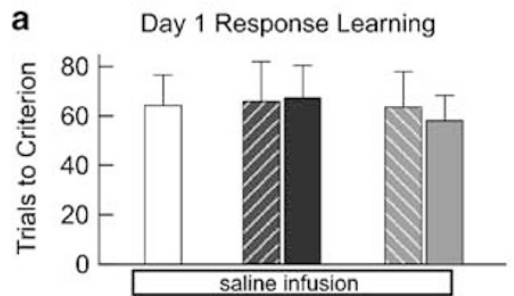

b

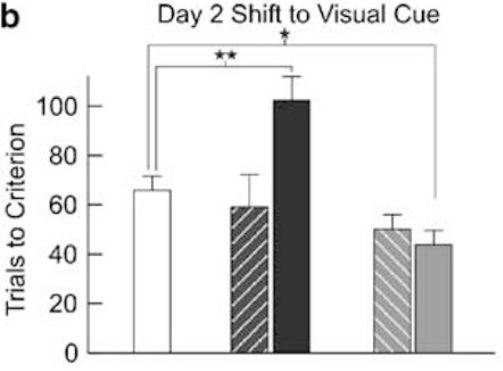

C

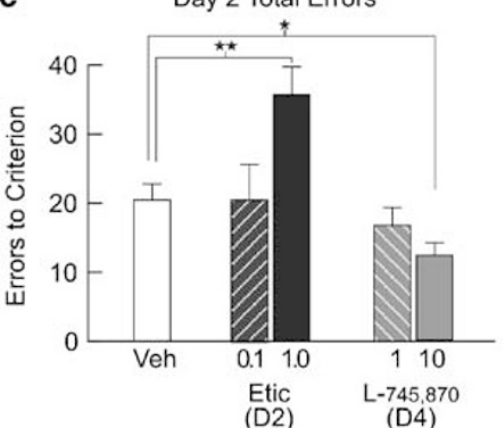

DA agonists

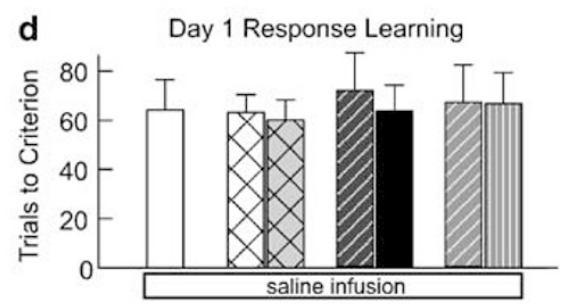

e

Day 2 Shift to Visual Cue

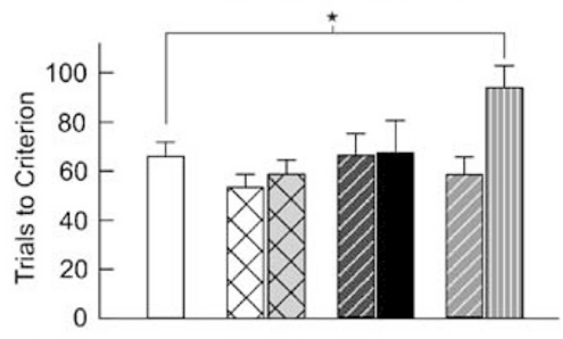

f

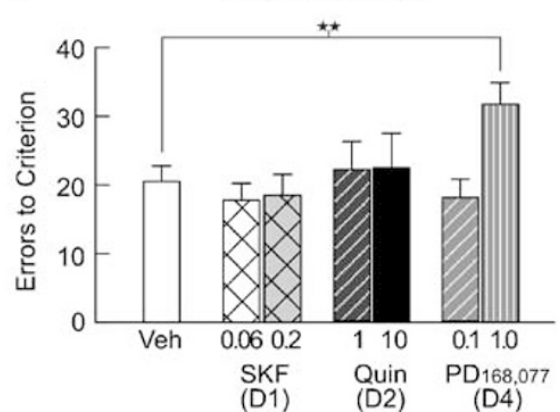

Figure 3 Experiment I: The effects of infusions of dopaminergic agents into the PFC on shifting from a response- to a visual-cue-based strategy. The data are expressed as means \pm SEM. (a, d) Trials to criterion on acquisition of the response discrimination following saline infusions on day I for all rats that received vehicle infusions (Veh, white bar) or infusions of DA antagonists (a) or agonists (b) into the PFC on day 2. (b, c) Trials to criterion (b) and errors to criterion (c) on the shift to the visual-cue discrimination on day 2 following infusions of either vehicle, 0.1 or $1.0 \mu \mathrm{g}$ of the D2 antagonists eticlopride (Etic), and infusions of 1.0 or $10.0 \mu \mathrm{g}$ of the D4 antagonist L-745,870. (e, f) Trials to criterion (e) and errors to criterion (f) on the shift to the visual-cue discrimination on day 2 following infusions of either vehicle (same data as in (b) and (c)), 0.06 or $0.2 \mu \mathrm{g}$ of the DI agonist SKF 8 I 297 (SKF), I.0 or I $0.0 \mu \mathrm{g}$ of the D2 agonist quinpirole (Quin), and infusions of 0.1 and I.0 $\mu$ g of the D4 agonist PD-I68,077. * $p<0.05$ and $* * p<0.01$, significantly different from the vehicle control group (Dunnett's test). 


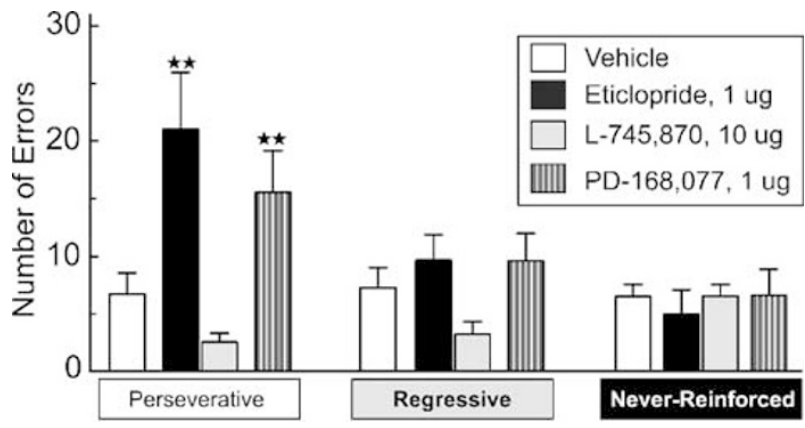

Figure 4 Analysis of the type of errors committed in Experiment I during the shift on day 2 for rats that displayed a significant difference from controls on the total number of errors. Infusions of $1.0 \mu \mathrm{g}$ of either the D2 antagonist eticlopride (black bar) or the D4 agonist PD-168,077 (gray striped bar) selectively increased the number of perseverative errors (left), but did not alter the number of regressive (middle) or never-reinforced (right) errors. Although infusions of the D4 antagonist L-745,870 significantly decreased the total number of errors, it did not cause a selective reduction in any one particular type of error (light gray bar). ** $p<0.0$ I, significantly different from vehicle control group (Dunnett's test).

$(\mathrm{F}(10,83)=1.452, \mathrm{NS})$. There were also no differences in the number of probe trials required to complete training on day $2(\mathrm{~F}(10,83)=0.86, \mathrm{NS})$.

DA antagonists. Multiple comparison analyses on the trials to criterion and error data were conducted using Dunnett's test. These tests showed that infusions of the D2 antagonist eticlopride dose-dependently impaired shifting from a response to a visual-cue discrimination strategy. Rats receiving the $1.0 \mu \mathrm{g}$ dose of eticlopride $(n=9)$ required significantly more trials to reach the criterion $(p<0.001$, Figure $3 \mathrm{~B}$, black bar) and made significantly more errors $(p<0.001$; Figure $3 c$, black bar). Infusions of the $1.0 \mu \mathrm{g}$ dose caused a selective increase in perseverative errors compared to saline controls $(p<0.001)$, but did not alter the number of regressive or never-reinforced errors (Figure 4). Infusions of the $0.1 \mu \mathrm{g}$ dose of eticlopride $(n=8)$ did not alter performance relative to control rats (Figure $3 \mathrm{~b}$ and c, black hatched bar).

In contrast, intra-PFC infusions of the D4 antagonist L745,870 improved shifting from a response to a visual-cue discrimination strategy. Infusions of the $1.0 \mu \mathrm{g}$ dose of L$745,870(n=9)$ produced a nonsignificant reduction in the number of trials to criterion (Figure $3 \mathrm{~b}$, gray hatched bar). However, rats receiving infusions of the $10.0 \mu \mathrm{g}$ dose $(n=9)$ required significantly fewer trials to reach the criterion $(p<0.05$; Figure $3 \mathrm{~b}$, gray bar) and made significantly fewer errors $(p<0.05$ (Figure $3 c$, gray bar).

DA agonists. Infusions of the D1 agonist SKF 81297 neither improved nor disrupted set-shifting; rats receiving either the $0.06 \mu \mathrm{g}(n=9)$ or the $0.2 \mu \mathrm{g}(n=10)$ dose did not differ significantly from control animals on the number of trials or errors to the criterion (Figure $3 \mathrm{e}$ and $\mathrm{f}$, cross-hatched bars). Similarly, infusions of either $1.0 \mu \mathrm{g}(n=7)$ or $10.0 \mu \mathrm{g}$ $(n=8)$ of the D2 agonist quinpirole did not alter the setshifting performance compared to control rats (Figure $3 \mathrm{e}$ and f). In contrast, infusions of the D4 agonist PD-168,077 disrupted set-shifting in a dose-dependent manner, with the
$1.0 \mu \mathrm{g}$ dose $(n=8)$ causing a significant increase in both trials to the criterion $(p<0.01)$ and errors to the criterion $(p<0.001$; Figure $3 e$ and $f$, gray striped bars). Subsequent analyses revealed that rats in this treatment group made significantly more perseverative errors compared to saline controls $(p<0.05$; Figure 4$)$, but did not differ from saline treated-animals in the number of regressive or neverreinforced errors. Infusions of the $0.1 \mu \mathrm{g}$ dose of PD-168,077 $(n=8)$ did not affect set-shifting.

\section{Experiment 2}

Day 1: visual-cue discrimination training. All rats in all groups reached criterion on the visual-cue discrimination task in substantially fewer trials than those initially trained on the response discrimination in Experiment 1, requiring approximately 45 trials to achieve criterion performance $($ mean $=45.4 \pm 2.9)$. Analysis of these data revealed no significant differences between groups $(\mathrm{F}(5,34)=0.44$, NS; Figure $5 \mathrm{a}$ and d). Rats took $34.5 \pm 4$ min to complete visualcue discrimination training, and there were no significant differences between groups on the average trials per minute $(\mathrm{F}(5,34)=0.33$, NS). There were no differences in the number of probe trials required to complete training on day $1(\mathrm{~F}(5,34)=0.39$, NS)

Day 2: shift to response discrimination. Analysis of the number of trials to reach the criterion on day 2 revealed a significant main effect of Drug Treatment $(\mathrm{F}(5,34)=$ 5.87, $p<0.001)$, a significant effect of Choice type $(\mathrm{F}(1,34)=98.81, \quad p<0.001)$, and no significant Treatment $\times$ Choice type interaction $(F(5,34)=1.40$, NS). A separate ANOVA analyzing the number of errors committed on Day 2 revealed a significant main effect of Drug Treatment $(\mathrm{F}(5,34)=6.46, p<0.001)$, a significant effect of Error Type $(\mathrm{F}(2,68)=25.68, p<0.001)$ and a significant Drug Treatment $\times$ Error Type interaction $(F(10,68)=2.57$, $p<0.05)$. Rats receiving saline infusions into the PFC $(n=9)$ required $81.8 \pm 12$ trials to achieve criterion performance (Figure $5 \mathrm{~b}$ and $\mathrm{e}$, white bar), and made an equivalent number of perseverative $($ mean $=12.0 \pm 2)$ and regressive (mean $=12.2 \pm 3$ ) errors, but substantially fewer never-reinforced errors (mean $=3.4 \pm 0.7$ ) (Figure 6). A separate one-way ANOVA conducted on the latency data exposed a significant difference between groups $(F(5,34)=4.35, p<0.01)$. This effect was due to the fact that rats treated with eticlopride displayed significantly faster running times (mean $=2.8 \pm 0.4$ trials per min) compared to saline-treated rats (mean $=2.0 \pm 0.2$ trials per minute; Dunnett's, $p<0.01$ ). There were no other significant differences between groups on this latency measure. In addition, there were no differences in the number of probe trials required to complete training on day $2(\mathrm{~F}(5,34)=$ $1.5, \mathrm{NS})$.

DA antagonists. As observed in Experiment 1, multiple comparisons using Dunnett's test confirmed that infusions of $1.0 \mu \mathrm{g}$ of the D2 antagonist eticlopride $(n=6)$ disrupted shifting from a visual-cue to a response discrimination strategy. D2 receptor blockade caused a significant increase in the number of trials to the criterion $(p<0.01$, Figure $5 \mathrm{~b}$, black bar) and errors to the criterion $(p<0.001$; Figure $5 c$, 
DA antagonists

DA agonists
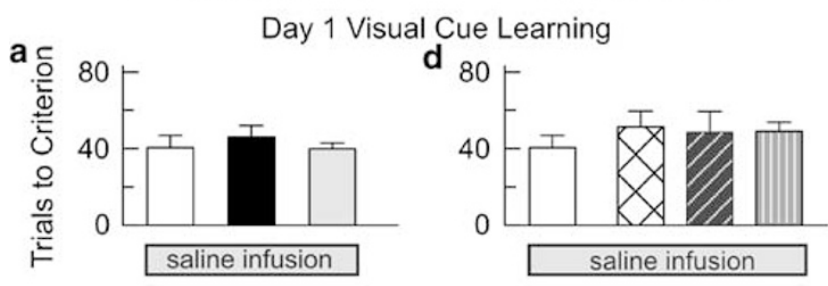

b
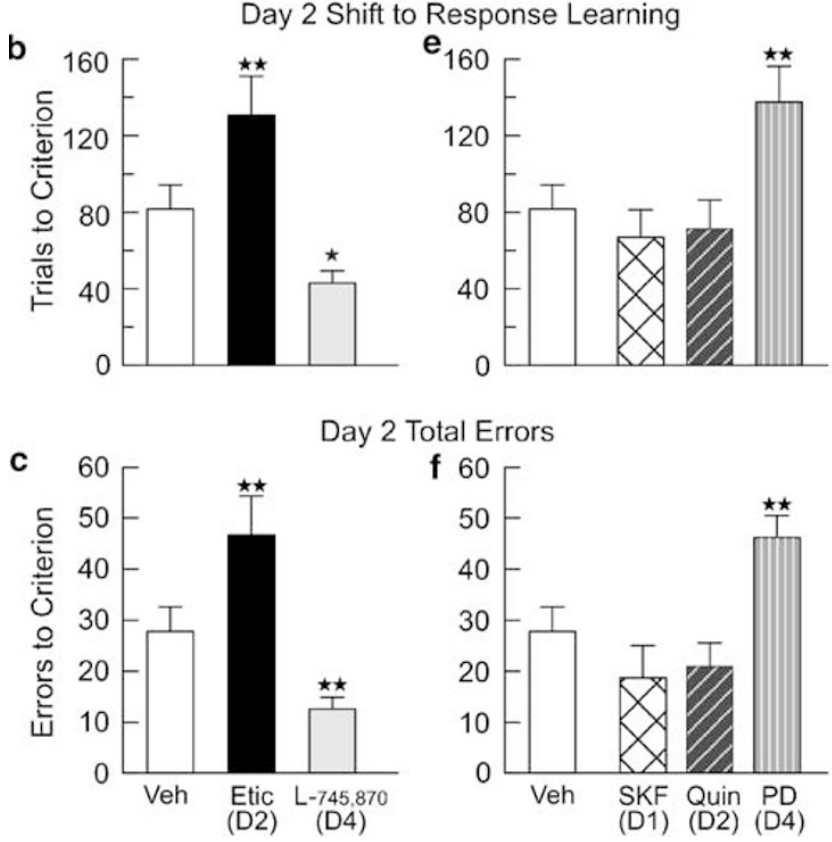

Figure 5 Experiment 2: The effects of infusions of dopaminergic agents into the PFC on shifting from a visual-cue- to a response-based strategy. The data are expressed as means \pm SEM. (a, d) Trials to criterion on acquisition of the visual-cue discrimination following saline infusions on day I for all rats that received vehicle infusions (Veh, white bar) or infusions of DA antagonists (a) or agonists (b) into the PFC on day 2. (b, c) Trials to criterion (b) and errors to criterion (c) on the shift to the response discrimination on day 2 following infusions of either vehicle, $1.0 \mu \mathrm{g}$ of the D2 antagonists eticlopride (Etic), and infusions of $10.0 \mu \mathrm{g}$ of the D4 antagonist L-745,870. (e, f) Trials to criterion (e) and errors to criterion (f) on the shift to the response discrimination on day 2 following infusions of either vehicle (same data as in b and c), $0.06 \mu \mathrm{g}$ of the DI agonist SKF 81297 (SKF), I.0 $\mu \mathrm{g}$ of the D2 agonist quinpirole (Quin), and infusions of I.0 $\mu \mathrm{g}$ of the D4 agonist PD- I68,077 (PD). *** $p<0.0$ I, significantly different from the vehicle control group (Dunnett's test).

black bar). Again, blockade of PFC D2 receptors caused a selective increase in perseverative errors compared to saline controls $(p<0.001)$, but did not alter the number of regressive or never-reinforced errors (Figure 6).

Blockade of D4 receptors in the PFC with $10 \mu \mathrm{g}$ of L$745,870(n=7)$ improved set-shifting in a manner similar to that observed in Experiment 1, causing a significant reduction in both the number of trials to reach the criterion $(p<0.05)$ and the number of errors $(p<0.005$; Figure $5 b$ and $c$, gray bar). In this experiment, infusions of L-745,870 did not alter the number of perseverative or neverreinforced errors, but did cause a significant decrease in regressive errors $(p<0.01$; Figure 6$)$, indicating that this treatment facilitated the maintenance of a new strategy.

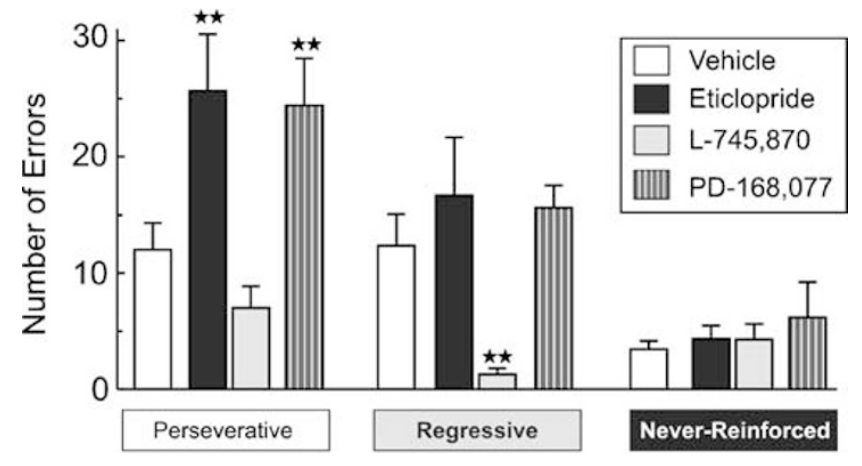

Figure 6 Analysis of the type of errors committed in Experiment 2 during the shift on day 2 for rats that displayed a significant difference from controls on the total number of errors. As observed in Experiment I, infusions of $1.0 \mu \mathrm{g}$ of either the D2 antagonist eticlopride (black bar) or the D4 agonist PD-168,077 (gray striped bar) selectively increased the number of perseverative errors (left), but did not alter the number of regressive (middle) or never-reinforced (right) errors. Infusions of the D4 antagonist L-745,870 (light gray bar) caused a selective reduction in the number of regressive errors. $* * * 0.01$, significantly different from the vehicle control group (Dunnett's test).

DA agonists. Stimulation of D1 receptors with SKF 81297 $(0.06 \mu \mathrm{g}, n=6)$ or D2 receptors with quinpirole $(1.0 \mu \mathrm{g}$, $n=7$ ) did not significantly alter the number of trials to reach the criterion or the number of errors to the criterion, although infusions of SKF 81297 did cause a marginal, but nonsignificant, reduction in the number of errors $(0.05<p<0.10)$ (Figure $5 \mathrm{e}$ and $\mathrm{f})$. In contrast, stimulation of $\mathrm{D} 4$ receptors with $\mathrm{PD}-168,077(1.0 \mu \mathrm{g}, n=6)$ replicated the effect observed in Experiment 1, significantly increasing both the number of trials to reach the criterion $(p<0.005)$ and errors to the criterion $(p<0.001$; Figure $5 \mathrm{e}$ and $\mathrm{f}$, gray striped bars). Analysis of the error type revealed that infusions of PD-168,077 significantly increased perseverative errors compared to saline treatment $(p<0.01)$, but did not alter the number of regressive or never-reinforced errors (Figure 6).

\section{DISCUSSION}

The main finding of the present study is that multiple DA receptor subtypes in the PFC regulate the ability to behave in a flexible manner and shift attentional set. Blockade of D2 receptors with eticlopride dose-dependently impaired shifting from a response to a visual-cue discrimination strategy and vice versa, causing a selective increase in perseverative responding, but left the ability to establish or maintain a new strategy intact. A similar deficit was observed following stimulation of D4 receptors in the PFC with PD-168,077, whereas infusions of agonists for D1 or D2 receptors neither impaired nor improved set-shifting. Of particular interest was the fact that antagonism of D4 receptors led to an improvement in set-shifting.

In the present study, all rats readily consumed food pellets on the maze and treatments that impaired performance either did not alter or decreased response latencies, suggesting that these effects were not due to motivational or motoric impairments. In addition, these impairments cannot be explained by a disruption of simple discrimina- 
tion learning, because lesions or inactivations of the PFC do not impair the initial learning of either visual or response based discriminations (Ragozzino et al, 1999; Chudasama et al, 2001). With respect to the relative selectivity of the drugs used in the present study, eticlopride is a highly selective and potent D2 antagonist with >300 times greater affinity for D2 vs D4 receptors, and does not appear to have any agonist actions on 5-HT receptors (Kohler et al, 1986; Seeman and Ulpian, 1988; Woodward et al, 1992; Durcan et al, 1995). Similarly, L-745,870 has $>1000$-fold selectivity for D4 vs D1/D2 receptors, and 100-2000 greater affinity for D4 receptors vs 5-HT 1A, 2A, 6, and 7 receptors (Patel et al, 1997; Huang et al, 2001). On the other hand, the relative affinity of PD-168,077 for D4 receptors is $>400$-fold greater compared to $\mathrm{D} 2$ receptors, and 20-400 greater $v s$ adrenergic $\alpha 1,2$, and 5-HT 1A and 2A receptors (Glase et al, 1997). Thus, although we cannot completely rule out that the alterations in behavioral flexibility observed here may have been due in part to actions on nondopaminergic receptors, it is likely that the effects of these compounds were mediated primarily by their actions on D2 and D4 receptors.

\section{Regulation of Set-Shifting by Both PFC D1 and D2 Receptors}

Previous psychopharmacological studies investigating the importance of DA transmission in behaviors regulated by the PFC have shown a prominent role for D1 receptors, whereas local blockade of D2 receptor within the PFC does not appear to disrupt cognitive processes such as working memory (Seamans et al, 1998; Sawaguchi, 2001). In contrast to these findings, the present data show that D2 receptors play a critical role in set-shifting, as blockade of these receptors in the PFC caused a selective increase in the number of perseverative errors. These data complement the findings of Ragozzino (2002), showing that D1 receptor blockade with SCH23390 also disrupted set-shifting using a similar procedure. In that study, blockade of D1 receptors in the PFC caused an increase in both perseverative and never-reinforced errors, suggesting that D1 receptor activity may serve to both inhibit the use of a previously rewarded strategy and facilitate the maintenance of a new behavioral response. The present findings are also in accordance with a recent report by Mehta et al (2004), showing that systemic administration of the D2 antagonist sulpiride in human subjects impairs task switching and attentional set-shifting. Collectively, these data suggest that, unlike working memory, the ability to shift attentional set is critically dependent on the activity of both $\mathrm{D} 1$ and $\mathrm{D} 2$ receptors in the PFC.

The question remains as to whether $\mathrm{D} 1$ and $\mathrm{D} 2$ receptors act cooperatively to facilitate one component of set-shifting or independently to regulate separate cognitive processes that enable shifting of behavioral strategies. In the present study, we were able to subdivide the type of errors made during the set-shift into perseverative, regressive, and never-reinforced errors. An increase in perseverative errors indicates a disruption in the ability to disengage from the previously effective but now inappropriate strategy, whereas regressive and never-reinforced errors are typically used as an index of the ability of the rat to learn and maintain a new, previously irrelevant strategy (Ragozzino et al, 2002;
Ragozzino, 2002). The fact that blockade of either D1 or D2 receptors in the PFC increases perseverative errors suggests that both receptor subtypes interact in a cooperative manner to facilitate the extinction of the previously learned response, which in turn may permit the learning of a new strategy. The notion that the PFC DA projection, acting on both D1 and D2 receptors, plays an important role in situations where environmental demands have changed (such as during extinction) is consistent with the findings that depletion of DA in the PFC or local blockade of DA receptors retards the extinction of a Pavlovian fear response (Morrow et al, 1999) and disrupts reinstatement of previously extinguished instrumental responding for food or cocaine (McFarland and Kalivas, 2001; Sun and Rebec, 2005).

Further insight into the mechanisms by which D1 and D2 receptors interact to mediate set-shifting comes from neurophysiological studies assessing the cooperative interactions of these receptors. A recent review by Seamans and Yang (2004) has proposed that D2 receptor modulation of PFC network activity, occurring when DA levels are particularly high, reduces inhibition and places the network in a more labile state, allowing it to process multiple stimuli and representations. However, more moderate extrasynaptic concentrations of DA activate D1 receptors and permit the stabilization of one particular representation by augmenting NMDA and other excitatory currents. During the set-shift used in the present study, animals quickly learn that the previous strategy is no longer relevant, and must shift attention to other cues in order to solve the task. It is during this initial period where PFC network activity must engage in multiple strategies, a state modulated putatively by D2 receptors (Trantham-Davidson et al, 2004). Once a particular strategy has been established, stabilization of this representation would be facilitated by D1 receptor activity. Thus, D2 receptor blockade would be expected to disrupt the ability of PFC networks to disengage from the previous strategy and compare the viability of alternative response options, causing a selective increase in perseverative errors (present study). On the other hand, D1 receptor antagonism would be expected to impede the stability of a novel strategy, impairing both the ability to shift off the old strategy (perseverative errors) and the maintenance of a new one (never-reinforced errors) (Ragozzino, 2002).

In contrast to the findings with DA antagonists, infusions of agonists for either D1 or D2 receptors into the PFC had no reliable effect on set-shifting. The lack of effect of SKF 81297 was particularly surprising, considering that local infusions of this compound at similar doses to those used in the present study have differential effects on attentional and working memory processes. Specifically, intra-PFC infusions of SKF 81297 at doses ranging from 0.06 to $0.3 \mu \mathrm{g}$ have been shown to impair performance on delayed response tasks when the baseline levels of performance are good (ie, during shorter delays), but these same doses improved working memory during longer delays, when baseline levels of performance were poor (Zahrt et al, 1997; Floresco and Phillips, 2001, Chudasama and Robbins, 2004). Similarly, infusions of a D2 agonist have also been shown to disrupt performance of a delayed response task conducted in a Umaze (Druzin et al, 2000). In the present study, we observed neither a disruption nor an improvement in set-shifting 
following infusions of 0.06 or $0.2 \mu \mathrm{g}$ of SKF 81297, although we did observe a slight, nonsignificant reduction in the number of errors committed by rats that were required to make the more difficult shift from a visual-cue- to a response-based strategy. When viewed collectively, it is apparent that, although suprathreshold stimulation of D1 receptors in the PFC can differentially modulate working memory, the same does not hold true for set-shifting functions mediated by the frontal lobes (at least at the doses tested here). In this regard, it is interesting to note that a recent study by Tunbridge et al (2004) reported that blockade of catechol-O-methyltransferase with systemic administration of tolcapone improved set-shifting at doses that were effective in augmenting PFC DA efflux. Thus, it is plausible that, whereas pharmacological activation of either D1 or D2 receptors in the PFC individually is insufficient to improve set-shifting, augmenting PFC DA transmission and concurrently activating both receptor subtypes may have beneficial effects on behavioral flexibility.

Local administration of D2 antagonists such as eticlopride has been shown to cause moderate $(\sim 50 \%)$ increases in PFC DA release in anesthetized rats (Chen and Pan, 2000). Therefore, it may be argued that the impairments produced by intra-PFC infusions of eticlopride were due in part to actions on presynaptic autoreceptors, which may in turn have led to increased activation of D4 receptors (see below). However, in the study mentioned above, increases in PFC DA efflux were evoked by a relatively low concentration of eticlopride $(1.0 \mathrm{nM}$ perfused locally within the PFC at $1.19 \mu \mathrm{l} / \mathrm{min}$ over $60 \mathrm{~min}$; Chen and Pan, 2000). Based on these findings, infusions of both the 0.1 and $1.0 \mu \mathrm{g}$ (ie, 0.26 and $2.6 \mathrm{nmol}$ ) doses of eticlopride would be expected to increase PFC DA efflux, yet only the $1.0 \mu \mathrm{g}$ dose disrupted set-shifting. Moreover, it is important to note that other treatments which have been shown to increase DA release in the PFC improve, rather than impair, set-shifting (Tunbridge et al, 2004; Lacroix et al, 2004; Hatcher et al, 2005). Thus, whereas increases in PFC DA efflux induced by infusions of eticlopride may have been a contributing factor to the deficits observed in the present study, it is likely that these impairments were due primarily to blockade of postsynaptic PFC D2 receptors.

\section{Opposing Effects of D4 Receptor Agonists and Antagonists on Set-Shifting}

In contrast to the above-mentioned findings with $\mathrm{D} 1$ and $\mathrm{D} 2$ receptor agonists, stimulation of PFC D4 receptors with PD-168,077 dose-dependently impaired shifting from a response to a visual-cue-based strategy and vice versa. As observed with D2 receptor blockade, D4 receptor stimulation resulted in a selective increase in perseverative errors, without altering the number of regressive or neverreinforced errors, which is indicative of a disruption in the ability to inhibit the use of a previously relevant strategy. These data suggest that increased D4 receptor activity can have a detrimental effect on cognitive functions mediated by the frontal lobes and are, to our knowledge, are the first to describe the effects of local infusion of D4 receptor agonists in the PFC. Recent neurophysiological and psychopharmacological studies suggest that the disruption of PFC function by excessive D4 receptor stimulation may be due in part to alterations of NMDA receptor activity. Stimulation of D4 receptors with PD-168,077 attenuates NMDA-mediated synaptic transmission in PFC pyramidal neurons by reducing NMDA-mediated currents and increasing the internalization of these receptors (Wang et al, 2003). With respect to the functional role of NMDA receptors in PFC, Stefani et al (2003) have shown that blockade of these receptors via intra-PFC infusion of MK801 impairs performance on a similar set-shifting task by selectively increasing perseverative errors, in a manner similar to that observed following infusions of PD-168,077 in the present study. Taken together, it is reasonable to propose that excessive stimulation of PFC D4 receptors may attenuate normal NMDA receptor function, and that this in turn may disrupt the patterns of NMDA-mediated activity of PFC neurons that are required for efficient performance of this task.

Perhaps the most surprising finding of the present study is that blockade of D4 receptors in PFC improved setshifting relative to vehicle-treated rats. At the first glance, it may seem counterintuitive that a disruption of an endogenous signaling pathway mediated by D4 receptors should lead to a beneficial effect on PFC functioning. However, there have been a number of previous reports that systemic administration of $\mathrm{D} 4$ antagonists can improve performance on tasks dependent on the PFC. For example, administration of the D4 antagonist NGD94-1 in monkeys reverses the phencyclidine-induced impairments on an object retrieval/detour task (Jentsch et al, 1999). Similarly, impairments in working memory induced by FG-7142, a pharmacological stressor that selectively increases PFC DA release, were attenuated by coadministration of the D4selective antagonist PNU-101,387G (Arnsten et al, 2000). Of particular interest is the recent report that injection of L-745,870 caused dose-dependent improvements in performance of a delayed alternation task in rats with poor levels of baseline performance (Zhang et al, 2004). As such, it is apparent that tonic D4 receptor activity may in some circumstances have a detrimental effect on cognitive functions mediated by the frontal lobes, perhaps by antagonizing the actions of D1 and/or D2 receptors on PFC function, and that blockade of these receptors, either systemically or locally, within the PFC can improve performance.

As mentioned above, stimulation of $\mathrm{D} 4$ receptors in vitro attenuates NMDA-mediated transmission in PFC pyramidal neurons (Wang et al, 2003), whereas blockade of these receptors with clozapine or L-745,870 can augment NMDA receptor activity (Chen and Yang, 2002; Jardemark et al, 2004). These findings suggest that infusions of L-745,870 in the present study may have alleviated a tonic, D4-mediated attenuation of NMDA receptor function, which in turn would be expected to enhance the activity of PFC neural networks, including those engaged during set-shifting (Stefani et al, 2003). In addition, systemic administration of D4 antagonists increases DA extracellular levels within the PFC, without altering the firing properties of midbrain DA neurons (Broderick and Piercey, 1998; Millan et al, 1998; Kawashima et al, 1999). These findings imply that local blockade of D4 receptors by infusion of L-745,870 could increase extracellular concentrations of PFC DA, 
perhaps by acting on presynaptic D4 receptors localized on DA terminals (Svingos et al, 2000). Taken together, it is reasonable to propose that the improvements in set-shifting observed in the present study following blockade of D4 receptors in the PFC may have been mediated by enhanced NMDA-mediated transmission and augmented PFC DA release, which would be expected to facilitate the patterns of activity within PFC neural networks that enable responding in a flexible manner.

\section{Clinical Implications}

It is becoming increasingly apparent that impairments in executive processes, such as attentional set-shifting, are a characteristic symptom of certain neuropsychiatric conditions where pathophysiology of the prefrontal cortical DA system is thought to be an underlying cause. For example, patients with schizophrenia present a variety of impairments in cognitive and executive functions subserved by the PFC, including perseverative deficits on the Wisconsin Card Sorting Task (Pantelis et al, 1999). The impairments observed in this disorder are thought to be due in part to alterations in mesocortical DA activity in the PFC, including increased metabolism of DA by catechol-O-methyltransferase (Egan et al, 2001), increased expression of PFC D4 receptors (Seeman et al, 1993; Tarazi et al, 2004), and decreases in D1 receptor activity (Friedman et al, 1999). Moreover, pharmacological treatments that increase PFC DA transmission, such as amphetamine or methylphenidate, can alleviate impairments in set-shifting associated with these disorders (Daniel et al, 1991; Yang et al, 2004). In addition, although treatment with D4 antagonists does not appear to be effective in alleviating psychosis (Kramer $e t$ al, 1997), atypical neuroleptics, which have a higher selectivity for D4 receptors than conventional antipsychotic medication, have also proven effective in treating some of the cognitive deficits observed in schizophrenia (Fujii et al, 1997; Harvey et al, 2003; Woodward et al, 2005). The data from the present study complement these findings and provide valuable insight into the neurochemical mechanisms that mediate the cognitive impairments in these disorders, which in turn may facilitate the development of novel pharmacotheraputic treatments designed to improve cognitive functioning. Thus, the finding that blockade of either D1 or D2 receptors, or stimulation of D4 receptors in the PFC, causes perseverative impairments in set-shifting suggests that the deficits in behavioral flexibility observed in schizophrenia may be due in part to increased D4 receptor activity, combined with hypoactivation of D1 and D2 receptors. However, the fact that antagonism of PFC D2 receptor alone can impair set-shifting suggests that blockade of these receptors with typical antipsychotic treatments may be partially responsible for some of the impairments in executive functioning observed in medicated schizophrenics. Therefore, the development of novel polypharmaceutical treatment strategies which could target PFC D4 receptors and mesolimbic D2 receptors selectively, while simultaneously increasing mesocortical DA release, may prove a more effective strategy for treating both the impairments in executive functioning as well as the psychoses that are present in schizophrenia.

\section{ACKNOWLEDGEMENTS}

This work was supported by a Discovery Grant from the Natural Science and Engineering Research Council of Canada and a Young Investigator Award from the National Alliance for Research on Schizophrenia and Depression (to SBF). We thank Leyla Tafreshi and Ryan McLaughlin for their assistance with behavioral testing, and we are eternally grateful to Annie Block and John Howland for their useful comments on the manuscript.

\section{REFERENCES}

Ariano MA, Wang J, Noblett KL, Larso ER, Sibley DR (1997). Cellular distribution of the rat D4 receptor protein in the CNS using anti-receptor antisera. Brain Res 752: 26-34.

Arnsten AF, Murphy B, Merchant K (2000). The selective dopamine D4 receptor antagonist, PNU-101387G, prevents stress-induced cognitive deficits in monkeys. Neuropsychopharmacology 23: 405-410.

Baddeley AD (1998). Recent developments in working memory. Curr Opin Neurobiol 8: 234-238.

Beyer CE, Steketee JD (2000). Intra-medial prefrontal cortex injection of quinpirole, but not SKF 38393, blocks the acute motor-stimulant response to cocaine in the rat. Psychopharmaacology 151: 211-218.

Birrell JM, Brown VJ (2000). Medial frontal cortex mediates perceptual attentional set shifting in the rat. J Neurosci 20: 4320-4324.

Broderick PA, Piercey MF (1998). Clozapine, haloperidol, and the D4 antagonist PNU-101387G: in vivo effects on mesocortical, mesolimbic, and nigrostriatal dopamine and serotonin release. J Neural Transm 105: 749-767.

Brozowski TS, Brown RM, Rosvold HE, Goldman PS (1979). Cognitive deficits caused by regional depletion of dopamine in prefrontal cortex of Rhesus monkey. Science 205: 929-932.

Chen L, Yang CR (2002). Interaction of dopamine D1 and NMDA receptors mediates acute clozapine potentiation of glutamate EPSPs in rat prefrontal cortex. J Neurophysiol 87: 2324-2336.

Chen NN, Pan WH (2000). Regulatory effects of D2 receptors in the ventral tegmental area on the mesocorticolimbic dopaminergic pathway. J Neurochem 74: 2576-2582.

Chudasama Y, Bussey TJ, Muir JL (2001). Effects of selective thalamic and prelimbic cortex lesions on two types of visual discrimination and reversal learning. Eur J Neurosci 14: 1009-1020.

Chudasama Y, Robbins TW (2004). Dopaminergic modulation of visual attention and working memory in the rodent prefrontal cortex. Neuropsychopharmacology 29: 1628-1636.

Crofts HS, Dalley JW, Collins P, Van Denderen JCM, Everitt BJ, Robbins TW et al (2001). Differential effects of 6-OHDA lesions of the frontal cortex and caudate nucleus on the ability to acquire attentional set. Cerebral Cortex 11: 1015-1026.

Daniel DG, Weinberger DR, Jones DW, Zigun JR, Coppola R, Handel S et al (1991). The effect of amphetamine on regional cerebral blood flow during cognitive activation in schizophrenia. J Neurosci 11: 1907-1917.

Dias R, Aggleton JP (2000). Effects of selective excitotoxic prefrontal lesions on acquisition of nonmatching- and matching-to-place in the T-maze in the rat: differential involvement of the prelimbic-infralimbic and anterior cingulate cortices in providing behavioral flexibility. Eur J Neurosci 12: 4457-4466.

Dias R, Robbins TW, Roberts AC (1997). Dissociable forms of inhibitory control within prefrontal cortex with an analog of the Wisconsin Card Sort Test: restriction to novel situations and independence from 'on-line' processing. J Neurosci 17: 9285-9297. 
Druzin MY, Kurzina NP, Malinina EP, Kozlov AP (2000). The effects of local application of D2 selective dopaminergic drugs into the medial prefrontal cortex of rats in a delayed spatial choice task. Behav Brain Res 109: 99-111.

Durcan MJ, Rigdon GC, Norman MH, Morgan PF (1995). Is clozapine selective for the dopamine D4 receptor? Life Sci 57: PL275-PL283.

Egan MF, Goldberg TE, Kolachana BS, Callicott JH, Mazzanti CM, Straub RE et al (2001). Effect of COMT Val108/158 Met genotype on frontal lobe function and risk for schizophrenia. Proc Natl Acad Sci USA 98: 6917-6922.

Floresco SB, Phillips AG (2001). Delay-dependent modulation of memory retrieval by infusion of a dopamine D1 agonist into the rat medial prefrontal cortex. Behav Neurosci 115: 934-939.

Friedman JI, Temporini H, Davis KL (1999). Pharmacologic strategies for augmenting cognitive performance in schizophrenia. Biol Psychiatry 45: 1-16.

Fujii DE, Ahmed I, Jokumsen M, Compton JM (1997). The effects of clozapine on cognitive functioning in treatment-resistant schizophrenic patients. J Neuropsychiatry Clin Neurosci 9: 240-245.

Fuster JM (2000). Executive frontal functions. Exp Brain Res 133: 66-70.

Glase SA, Akunne HC, Georgic LM, Heffner TG, MacKenzie RG, Manley PJ et al (1997). Substituted [(4-phenylpiperazinyl)methyl]benzamides: selective dopamine D4 agonists. J Med Chem 40: 1771-1772.

Goldman-Rakic PS (1995). Cellular basis of working memory. Neuron 14: 477-485.

Harvey PD, Green MF, McGurk SR, Meltzer HY (2003). Changes in cognitive functioning with risperidone and olanzapine treatment: a large-scale, double-blind, randomized study. Psychopharmacology 169: 404-411.

Hatcher PD, Brown VJ, Tait DS, Bate S, Overend P, Hagan JJ et al (2005). 5-HT6 receptor antagonists improve performance in an attentional set shifting task in rats. Psychopharmacology, April 21 [Epub ahead of print].

Huang Y, Kegeles LS, Bae S, Hwang D, Roth BL, Savage JE et al (2001). Synthesis of potent and selective dopamine $\mathrm{D}(4)$ antagonists as candidate radioligands. Bioorg Med Chem Lett 11: 1375-1377.

Jardemark K, Marcus MM, Konradsson A, Svensson TH (2004). The combination of nicotine with the D2 antagonist raclopride or the weak D4 antagonist L-745,870 generates a clozapine-like facilitation of NMDA receptor-mediated neurotransmission in pyramidal cells of the rat medial prefrontal cortex. Int $J$ Neuropsychopharmacol 7: 1-6.

Jentsch JD, Taylor JR, Redmond Jr DE, Elsworth JD, Youngren KD, Roth RH (1999). Dopamine D4 receptor antagonist reversal of subchronic phencyclidine-induced object retrieval/detour deficits in monkeys. Psychopharmacology 142: 78-84.

Kawashima N, Okuyama S, Omura T, Chaki S, Tomisawa K (1999). Effects of selective dopamine D4 receptor blockers, NRA0160 and L-745,870, on A9 and A10 dopamine neurons in rats. Life Sci 65: 2561-2571.

Kohler C, Hall H, Gawell L (1986). Regional in vivo binding of the substituted benzamide $[3 \mathrm{H}]$ eticlopride in the rat brain: evidence for selective labelling of dopamine receptors. Eur J Pharmacol 120: 217-226.

Kramer MS, Last B, Getson A, Reines SA (1997). The effects of a selective D4 dopamine receptor antagonist (L-745,870) in acutely psychotic inpatients with schizophrenia. D4 Dopamine Antagonist Group. Arch Gen Psychiatry 54: 567-572.

Lacroix LP, Dawson LA, Hagan JJ, Heidbreder CA. (2004). 5-HT6 receptor antagonist SB-271046 enhances extracellular levels of monoamines in the rat medial prefrontal cortex. Synapse 51: $158-164$
Lebron K, Milad MR, Quirk GJ (2004). Delayed recall of fear extinction in rats with lesions of ventral medial prefrontal cortex. Learn Mem 11: 544-548.

McFarland K, Kalivas PW (2001). The circuitry mediating cocaineinduced reinstatement of drug-seeking behavior. J Neurosci 21: 8655-8663.

Mehta MA, Manes FF, Magnolfi G, Sahakian BJ, Robbins TW (2004). Impaired set-shifting and dissociable effects on tests of spatial working memory following the dopamine D2 receptor antagonist sulpiride in human volunteers. Psychopharmacology 176: $331-342$.

Millan MJ, Newman-Tancredi A, Brocco M, Gobert A, Lejeune F, Audinot $\mathrm{V}$ et al (1998). S 18126 ([2-[4-(2,3-dihydrobenzo[1,4]dioxin-6-yl)piperazin-1-yl methyl]indan-2-yl]), a potent, selective and competitive antagonist at dopamine D4 receptors: an in vitro and in vivo comparison with L 745,870 (3-(4-[4-chlorophenyl]piperazin-1-yl)methyl-1H-pyrrolo[2, 3b]pyridine) and raclopride. J Pharmacol Exp Ther 287: 167-186.

Morrow BA, Elsworth JD, Rasmusson AM, Roth RH (1999). The role of mesoprefrontal dopamine neurons in the acquisition and expression of conditioned fear in the rat. Neuroscience 92: 553-564.

Mrzijak L, Bergson C, Pappy M, Huff R, Levenson R, GoldmanRakic PS (1996). Localization of dopamine D4 receptors in GABAergic neurons of the primate brain. Nature 381: 245-248.

Murphy BL, Arnsten AF, Goldman-Rakic PS, Roth RH (1996). Increased dopamine turnover in the prefrontal cortex impairs spatial working memory performance in rats and monkeys. Proc Natl Acad Sci USA 93: 1325-1329.

Pantelis C, Barber FZ, Barnes TR, Nelson HE, Owen AM, Robbins TW (1999). Comparison of set-shifting ability in patients with chronic schizophrenia and frontal lobe damage. Schizophr Res 37: 251-270.

Patel S, Freedman S, Chapman KL, Emms F, Fletcher AE, Knowles $M$ et al (1997). Biological profile of L-745,870, a selective antagonist with high affinity for the dopamine D4 receptor. J Pharmacol Exp Ther 283: 636-647.

Paxinos G, Watson C (1998). The Rat Brain in Stereotaxic Coordinates, 4th edn. Academic Press: San Diego.

Phillips AG, Ahn S, Floresco SB (2004). Magnitude of dopamine release in medial prefrontal cortex predicts accuracy of memory on a delayed response task. J Neurosci 24: 547-553.

Ragozzino ME (2002). The effects of dopamine D1 receptor blockade on the prelimbic-infralimbic areas on behavioral flexibility. Learn Mem 9: 18-28.

Ragozzino ME, Ragozzino KE, Mizumori SJ, Kesner RP (2002). Role of the dorsomedial striatum in behavioral flexibility for response and visual cue discrimination learning. Behav Neurosci 116: 105-115.

Ragozzino ME, Detrich S, Kesner RP (1999). Involvement of the prelimbic-infralimbic areas of the rodent prefrontal cortex in behavioral flexibility for place and response learning. J Neurosci 19: 4585-4594.

Reeve WV, Schandler SL (2001). Frontal lobe functioning in adolescents with attention deficit hyperactivity disorder. Adolescence 36: 749-765.

Roberts AC, De Salvia MA, Wilkinson LS, Collins P, Muir JL, Everitt BJ et al (1994). 6-Hydroxydopamine lesions of the prefrontal cortex in monkeys enhance performance on an analog of the Wisconsin Card Sort Test: possible interactions with subcortical dopamine. J Neurosci 14: 2531-2544.

Romanides AJ, Duffy P, Kalivas PW (1999). Glutamatergic and dopaminergic afferents to the prefrontal cortex regulate spatial working memory in rats. Neuroscience 92: 97-106.

Sawaguchi T (2001). The effects of dopamine and its antagonists on directional delay-period activity of prefrontal neurons in monkeys during an oculomotor delayed-response task. Neurosci Res 41: 115-128. 
Sawaguchi T, Matsumura M, Kubota K (1990). Catecholaminergic effects on neuronal activity related to a delayed response task in monkey prefrontal cortex. J Neurophysiol 63: 1385-1400.

Seamans JK, Durstewitz D, Christie B, Stevens CF, Sejnowski TJ (2001a). Dopamine D1/D5 receptor modulation of excitatory synaptic inputs to layer V prefrontal cortex neurons. Proc Natl Acad Sci USA 98: 301-306.

Seamans JK, Floresco SB, Phillips AG (1998). $D_{1}$ receptor modulation of hippocampal-prefrontal cortical circuits integrating spatial memory with executive functions in the rat. J Neurosci 18: 1613-1621.

Seamans JK, Gorelova N, Durstewitz D, Yang CR (2001b). Bidirectional dopamine modulation of GABAergic inhibition in prefrontal cortical pyramidal neurons. J Neurosci 21: 3628-3638.

Seamans JK, Yang CR (2004). The principal features and mechanisms of dopamine modulation in the prefrontal cortex. Prog Neurobiol 74: 1-58.

Seeman P, Guan HC, Van Tol HH (1993). Dopamine D4 receptors elevated in schizophrenia. Nature 365: 441-445.

Seeman P, Ulpian C (1988). Dopamine D1 and D2 receptor selectivities of agonists and antagonists. Adv Exp Med Biol 235: $55-63$.

Sesack SR, King SW, Bressler CN, Watson SJ, Lewis DA (1995). Electron microscopic visualization of dopamine D2 receptors in the forebrain: cellular, regional, and species comparisons. Soc Neurosci Abstr 21: 365.

Shah AA, Sjovold T, Treit D (2004). Selective antagonism of medial prefrontal cortex D4 receptors decreases fear-related behaviour in rats. Eur J Neurosci 19: 3393-3397.

Slamecka NJ (1968). A methodological analysis of shift paradigms in human discrimination learning. Psychol Bull 69: 423-438.

Stefani MR, Groth K, Moghaddam B (2003). Glutamate receptors in the rat medial prefrontal cortex regulate set-shifting ability. Behav Neurosci 117: 728-737.

Sun W, Rebec GV (2005). The role of prefrontal cortex D1-like and D2-like receptors in cocaine-seeking behavior in rats. Psychopharmacology 177: 315-323.

Svingos AL, Periasamy S, Pickel VM (2000). Presynaptic dopamine $\mathrm{D}(4)$ receptor localization in the rat nucleus accumbens shell. Synapse 36: 222-232.

Tarazi FI, Zhang K, Baldessarini RJ (2004). Dopamine D4 receptors: beyond schizophrenia. J Recept Signal Transduct Res 24: 131-147.

Trantham-Davidson H, Neely LC, Lavin A, Seamans JK (2004). Mechanisms underlying differential D1 versus D2 dopamine receptor regulation of inhibition in prefrontal cortex. J Neurosci 24: 10652-10659.
Tseng KY, O’Donnell P (2004). Dopamine-glutamate interactions controlling prefrontal cortical pyramidal cell excitability involve multiple signaling mechanisms. J Neurosci 24: 5131-5139.

Tunbridge EM, Bannerman DM, Sharp T, Harrison PJ (2004). Catechol-O-methyltransferase inhibition improves set-shifting performance and elevates stimulated dopamine release in the rat prefrontal cortex. J Neurosci 24: 5331-5335.

Vincent SL, Khan Y, Benes FM (1993). Cellular distribution of dopamine D1 and D2 receptors in rat medial prefrontal cortex. J Neurosci 13: 2551-2564.

Wang X, Zhong P, Gu Z, Yan Z (2003). Regulation of NMDA receptors by dopamine D4 signaling in prefrontal cortex. J Neurosci 23: 9852-9861.

Wang X, Zhong P, Yan Z (2002). Dopamine D4 receptors modulate GABAergic signaling in pyramidal neurons of prefrontal cortex. J Neurosci 22: 9185-9193.

Wedzony K, Chocyk A, Mackowiak M, Fijal K, Czyrak A (2000). Cortical localization of dopamine D4 receptors in the rat brain-immunocytochemical study. J Physiol Pharmacol 51: 205-221.

Williams GV, Goldman-Rakic PS (1995). Modulation of memory fields by dopamine D1 receptors in prefrontal cortex. Nature 376: $572-575$.

Woodward ND, Purdon SE, Meltzer HY, Zald DH (2005). A metaanalysis of neuropsychological change to clozapine, olanzapine, quetiapine, and risperidone in schizophrenia. Int $J$ Neuropsychopharmacol 23: 1-16.

Woodward RM, Panicker MM, Miledi R. (1992). Actions of dopamine and dopaminergic drugs on cloned serotonin receptors expressed in Xenopus oocytes. Proc Natl Acad Sci USA 89: 4708-4712.

Yang P, Chung LC, Chen CS, Chen CC (2004). Rapid improvement in academic grades following methylphenidate treatment in attention-deficit hyperactivity disorder. Psychiatry Clin Neurosci 58: $37-41$

Zahrt J, Taylor JR, Mathew RG, Arnsten AF (1997). Supranormal stimulation of D1 dopamine receptors in the rodent prefrontal cortex impairs spatial working memory performance. J Neurosci 17: 8528-8535.

Zhang K, Grady CJ, Tsapakis EM, Andersen SL, Tarazi FI, Baldessarini RJ (2004). Regulation of working memory by dopamine D4 receptor in rats. Neuropsychopharmacology 29: $1648-1655$.

Zheng P, Zhang XX, Bunney BS, Shi WX (1999). Opposite modulation of cortical N-methyl-D-aspartate receptor-mediated responses by low and high concentrations of dopamine. Neuroscience 91: 527-535. 